\title{
How emotionally intelligent are pre-service teachers?
}

Roisin P. Corcoran, Department of Psychology, Yale University, New Haven, CT, USA

Roland Tormey, Centre de Recherche de d'Appui pour la Formation et ses Technologies (CRAFT), École Polytechnique Fédérale de Lausanne, Lausanne, Switzerland

\begin{abstract}
Although there is evidence that teacher emotional intelligence is important for pupil adjustment and learning and for teachers in managing the emotional demands of their work, little is known about the levels of emotional skill of teachers and beginning teachers. Using Mayer and Salovey's emotional intelligence (EI) model and the MSCEIT test of EI, this study investigates how emotionally skilled student teachers are $(\mathrm{N}=352)$. Results show lower than average levels of EI among student teachers, but with important differences between students and across emotional skill areas. The implications of the findings for pre-service teacher education are explored.
\end{abstract}

(postprint version

Teaching and Teacher Education Volume 28, Issue 5, July 2012, Pages 750-759 http://www.sciencedirect.com/science/article/pii/S0742051X1200042X) 


\section{How emotionally intelligent are pre-service teachers?}

\section{Introduction}

The decades since the early 1980s have seen something of an "emotional revolution" in psychology (Sutton \& Wheatley, 2003, p. 328) and by the mid to late 1990s this had impacted on teacher research and teacher education research. The special edition of the Cambridge Journal of Education (edited by Nias, 1996) along with several articles by Hargreaves $(1998,2000)$ attracted some much needed attention to the area. As a result, there is a growing body of literature looking at the emotional context of teaching, learning and learning to teach (Boyle, Borg, Falzon, \& Baglioni, 1995; Bullough, Knowles, \& Crow, 1991; Emmer, 1994; Erb, 2002; Evelein, Korthagen, \& Brekelmans, 2008; Hargreaves, 1998, 2000; Helsing, 2007; Hoekstra \& Korthagen, 2011; Intrator, 2006; Kyriacou, 1987, 1998; Lortie, 1975; Meyer, 2009; Rosiek, 2003; van Dick \& Wagner, 2001). There has also been some focus on the sort of teacher education needed to support the development of teachers who can utilise emotions effectively (Intrator, 2006; Rosiek, 2003; Whitcomb, Borko, \& Liston, 2008).

Much of the existing research on teacher emotions takes a broadly qualitative and descriptive approach to emotions; describing the range, depth and contexts in which emotions are experienced, managed and displayed. While there is evident value in such studies, there are also clear limitations. Recognising that teaching and beginning teaching are emotionally charged experiences does not actually tell us how competent teachers and beginning teachers are in productively working with and problem-solving using emotional information and in which areas they most need to develop their skills. That is the issue which this paper addresses with respect to pre-service teacher education.

In the next section the emotional intelligence (EI) framework developed by Mayer \& Salovey (1997) is described, its importance with respect to teachers' work is assessed and potential questions such as the relationships between gender and emotional intelligence and between emotional intelligence and different entry pathways into pre-service teacher education are identified. Thereafter the methodology used in the research is described and then the findings from a large study on EI in pre-service teacher education students are reported. The discussion section identifies which emotional skill areas are most and least problematic for the student teachers studied and which need to be addressed in their teacher education programs.

\section{The emotional intelligence framework and teachers' work}

The question as to how levels of emotional skills or competence can be measured is one that is fraught with difficulty. Indeed, some would argue that "the intangible emotional and empathic qualities which make a 'good teacher' from the viewpoint of the students cannot be measured" (Constanti and Gibbs [2004, p. 247]; cited in O'Connor, 2008, p. 117) while others (Hargreaves, 1998) argue that to see emotions in terms of 'skills' is to decouple the emotional from its social context. At the same time, teacher educators are concerned with student skills (as well as with an understanding of the social contexts of learning) and so some account of emotional skills cannot be completely neglected. Measuring emotional skills is what emotional intelligence (EI) models (Bar-On, 1997b; Goleman, 1995; Mayer \& Salovey, 1997) focus on. The concept was originally coined by Peter Salovey and John D. Mayer (1990) as a way of recognising that emotions and emotional information were an important part of problem solving and adaptation in 
everyday life. The term was broadly popularised by Daniel Goleman's (1995) book entitled, Emotional Intelligence, Why it can matter more than IQ. It is worth noting that there is, as of yet, little agreement as to how emotional competences are to be understood, made operational or measured (Humphrey, Curran, Morris, Farrell, \& Woods, 2007). Indeed, despite the shared use of the term by different research groups, EI is today understood in what can be characterised as two broadly different ways:

- As a restricted set of mental abilities involving the processing of emotional information (Mayer \& Salovey, 1997; Salovey \& Mayer, 1990) and being assessed through the use of a test of emotional problem solving and skills known as the Mayer-Salovey-Caruso Emotional Intelligence Test (MSCEIT; Mayer, Salovey, \& Caruso, 2002a);

- As a broad range of personality traits, skills and abilities (Bar-On, 1997b; Goleman, 1995) assessed through self-report or $360^{\circ}$ evaluation models (not unlike a personality inventory) such as the EQ-i (Bar-On, 1997a), and the ECI (Boyatzis, Goleman, \& Hay/McBer., 1999; Boyatzis, Goleman, \& Rhee, 2000). A complete evaluation of the strengths and weakness of each model is provided elsewhere (Corcoran \& Tormey, in press), however it should be noted that the Mayer and Salovey model of EI has a number of distinct strengths that make it suitable for work in this area. First, the more specific and limited focus of Salovey and Mayer on cognitive skills of processing emotional information means that their concept of EI measures something different than what is already measured through broad personalitytype variables (Mayer, Roberts, \& Barsade, 2008; O'Connor \& Little, 2003). Second, the MSCEIT tests a set of skills directly rather than relying on self-report or $360^{\circ}$ evaluation mechanisms, something which adds significantly to the sense that it is a valid measure (Dunning, Heath, \& Suls, 2004). Put simply, “one’s perceived intelligence is considerably different from one's actual intelligence” (Mayer, Salovey, \& Caruso, 2004, p. 203).

Salovey and Mayer have defined emotional intelligence as "the ability to perceive and express emotions, to understand and use them, and to manage emotions so as to foster personal growth" (Salovey, Bedwell, Detweiler, \& Mayer, 2000, p. 506), and have used this definition to develop a framework of skills or abilities which can be tested to give rise to an overall measure of emotional intelligence (EIQ) as well as four branch-scores, each representing a class of skills. The four categories utilized are:

- Perception, Appraisal, and Expression of Emotion (PEIQ)

- Using Emotion to Facilitate Thinking (FEIQ)

- Understanding and Analyzing Emotional Information (UEIQ); and

- Regulation of Emotion (MEIQ).

It should be noted that the term "intelligence" can sometimes still be interpreted as referring to innate or fixed abilities, despite significant evidence that social and environmental factors impact both upon the cognitive skills that people develop and upon the skills that are valued and required in their social setting (Neisser et al., 1996). In this study, no assumptions are made about emotional intelligence being innate or fixed. Rather, the EI model is seen as providing a framework for conceptualising emotional skills, and the MSCEIT as a way of testing those skills.

There are good grounds for seeing a high level of EI as a valuable part of the teachers' skills set (Corcoran, 2011). For example, EI plays an important role in the development of pro-social behavior, better social functioning and quality interpersonal relationships with peers and teachers (Brackett, Mayer, \& Warner, 2004; Lopes et al., 2004; Mayer et al., 2008). Teachers who are more skilled at regulating their emotions tend to report less burnout and greater job satisfaction; they also experience greater 
positive affect while teaching and receive more support from the principals with whom they work (Brackett, Palomera, Mojsa-Kaja, Reyes, \& Salovey, 2010). Developing teachers' emotional skills can create a more positive and effective learning environment which is important for the motivation and productivity of both teachers and students (Durlak, Weissberg, Dymnicki, Taylor, \& Schellinger, 2011; Jennings \& Greenberg, 2008; Rimm-Kaufman, Fan, Chiu, \& You, 2007; Sutton \& Wheatley, 2003). Furthermore, the emotional skills of teachers' influences student conduct, engagement, attachment to school, and academic performance (Baker, 1999; Duckworth, Kirby, Gollwitzer, \& Oettingen, in press; Hawkins, 1999; Schaps, Battistich, \& Solomon, 1996; Wentzel, 2002). The ability to perceive emotion in self and others has repeatedly been identified as important for teachers (Roseik, 2003; Intrator, 2006; Helsing, 2007; Whitcomb et al., 2008). Recognising that different emotional states can facilitate or hinder different cognitive processes (Isen, Daubman, \& Nowicki, 1987; Palfai \& Salovey, 1993) also means that the ability to regulate emotions in the self and others is likely to have importance for teachers (Corcoran \& Tormey, in press). Such competence is likely to be as important for pre-service teachers who are engaged both in the emotional processes of learning and of teaching at the same time, and for whom beginning teaching has been described as akin to an emotional whirlpool (Erb, 2002) marked by a "dramatic range of intense emotions and passions” (2006, p. 235).

Yet despite all this, there is relatively little research on teachers and on beginning teachers using the emotional intelligence framework. While Byron (2001), reported that novice teachers scored no differently on measures of emotional intelligence than the normative sample, Brackett et al. (2010) found that the mean emotional regulation ability score for a sample of secondary school teachers in England was about 0.5 of a standard deviation lower than those reported in the normative sample. Similarly Authors (2010)(2010)(2010)(2010)(2010)(2010)(2010)(2010)(2010)(2010)(2010)(2010)(2010 )(2010)(2010)(2010)(2010)found that the overall EIQ score of a sample of Irish teachers was about 0.3 of a standard deviation below international norms.

It is difficult to draw firm conclusions from this small number of studies, carried out with relatively small samples. For example, research using the MSCEIT with larger data sets has found that females have, on average, slightly higher EQI than males (though of course this describes only the averages and so there are many males with EIQ scores higher than many females) (Mayer, Salovey, \& Caruso, 2002b, p. 32). A number of studies (Briton \& Hall, 1995; Fischer \& Manstead, 2000) suggest that women are stereotyped as being the more emotional sex, and believed to experience and express emotions more often. Some empirical studies have found women to be more intensely expressive of most positive and many negative emotions than were men (Brody \& Hall, 2000, p. 344), with the possible exception of anger (Coats \& Feldman, 1996; Dimberg \& Lundquist, 1990). At the same time, Barrett, Robin, Pietromonaco, and Eyssell (1998) found no gender differences in reported experiences when men and women report how they feel in the moment ("how anxious do you feel right now?"), as opposed to reporting from hindsight ("how anxious were you doing last week's exam?”), or at a global level (“how often do you feel sad or depressed?”). Hochschild (2003, pp. 164-170) argues that if there are differences between men and women in the management of emotion these are related to both gendered differences in expectations of masculinity and femininity and to differences in power and status, with women being required to manage emotion to a greater degree because they are more likely to be in positions of lower status. It is hard to know what this might mean with respect to potential gender differences in emotional skills among student teachers where females 
and males share a common status of student teacher, but may at the same time differ both in their gender socialisation and in gendered expectations of emotional display rules. Existing studies are too small to draw on empirical data in addressing such questions.

Existing samples have also been too small to allow other important differences to be explored. With pre-service teachers, for example, much attention has been paid in the last decade to the perceived need for a range of pathways into the teaching profession. A study based on nine-countries (Conway, Murphy, Rath, \& Hall, 2009) highlights that many countries allow for entry into teaching through either a concurrent or a consecutive teacher education route, while in some countries deregulation has led to entry through workplace-based qualifications or through emergency licences. Entry onto teacher education programs is often based on academic criteria alone and critics of this system argue that the entry criteria do not necessarily emphasise the competences needed for effective teaching (OECD, 2005). Some posit that "personal suitability data" should accompany academic criteria and suggest "it is desirable to seek to recruit more mature students with varied work experience" which would enrich the teaching profession (Coolahan, 2003, p. 22). As it stands, the existing data on emotional intelligence does not allow such issues to be addressed; that is, whether there are differences between pre-service teachers depending on whether they are selected by academic criteria alone or through combining academic criteria with other "suitability"type criteria.

In summary, there is a growing body of literature on teacher emotions, much of it qualitative, descriptive and contextual. There is evidence that a high level of emotional skill is of benefit to teachers and their pupils, but there is limited evidence about the levels of emotional intelligence or skill that pre-service teachers have. It is also unclear as to whether or not student teachers' emotional intelligence levels are associated with gender or with the route of entry into pre-service teacher education. The EI model developed by Mayer and Salovey and the MSCEIT provide a conceptual framework for making sense of what are the specific emotional skills that student teachers have or lack. This in turn has implications for what should be addressed in teacher education.

\section{Methodology}

The question which is at the core of this study is: How competent are student teachers in (a) perceiving emotions in self and others, (b) using emotions to facilitate particular types of thought (c) understanding emotional information and (d) managing emotion?

In order to answer this question, the MSCEIT V2.0 was administered to a diverse group of Irish post-primary student teachers $(\mathrm{N}=352)$. Given that the MSCEIT was being used in a new context a confirmatory factor analysis was conducted to test the structural validity of the four branch model used in the MSCEIT in the Irish context.

\subsection{Participants}

Student teachers, from the third year of a four-year undergraduate program (UG) and from a one-year graduate diploma (GD) program in an Irish university, were invited to participate in this study aimed at assessing their level of emotional intelligence. Of the students that applied, undergraduate students were selected using a stratified random sampling technique. Since numbers in the graduate diploma program were lower, all graduate diploma students who agreed to participate in the research were selected. The 
MSCEIT was administered to both groups of students. This entire process was then repeated the following year. The second cohort (in cycle two) were students on the same education courses at the same point in their studies and drawn from the same applicant pool as the previous participants. This gave MSCEIT (emotional intelligence) data for 352 students in total (see Table 1), 205 female and 147 male. Given the gender imbalance in the college courses, the male student teachers were largely drawn from the engineering, construction and technology programs and female students were largely drawn from physical education, science, languages, music and business programs.

The Organization for Economic Co-operation and Development (OECD) report entitled, Teachers matter: Attracting, developing and retaining effective teachers points to the high social status and competitiveness for entry traditionally enjoyed by the teaching career in Ireland, Finland and Korea (OECD, 2005). Entry to the UG teacher education programs (concurrent model in secondary teacher education) that participated in the study is largely by academic grades only, although entry into the GD programs (consecutive model in secondary teacher education) is also based on performance at an interview. A number of other countries - Austria, Australia, the Czech Republic, England, Finland, Israel, the Netherlands, Northern Ireland, Scotland, the Slovak Republic, Sweden and Wales - similarly offer both models in preparing secondary school teachers (OECD, 2005). However, entry routes to pre-service teacher education programs are a frequent international debate (Cochran-Smith \& Fries, 2006; OECD, 2005).

Table 1: Course of study of participants

\begin{tabular}{lc}
\hline Program & Number of participants \\
\hline Undergraduate Programs & 51 \\
Physical Education (P.E.) & 45 \\
Engineering Education & 51 \\
Construction Education & 50 \\
Science Education & \\
Graduate Diploma Programs & 48 \\
Business Education & 30 \\
Physical Education (P.E) & 21 \\
Modern Languages Education & \\
Technology (Construction and Engineering) & 18 \\
Education & 38 \\
Music Education &
\end{tabular}

\subsection{Instrument}

The MSCEIT V2.0 was administered to all 352 student teachers. The MSCEIT is composed of 141-items which make up eight 'task' scales, which in turn make up the four 'branch' scales that form the basis of the Mayer and Salovey model of EI. According to Mayer et al. (2002b, p. 70) it “provides an estimate of a person's ability by having them solve problems. The MSCEIT asks you to solve problems about emotions, or problems that require the use of emotion.” The MSCEIT yields a number of different scores, and as with other intelligence tests, MSCEIT scores are constructed so that the average score for the population would be expected to be 100, with a standard deviation of 15. The available scores include a total Emotional Intelligence score (EIQ) and four branch scores which are Perceiving Emotions (PEIQ), Facilitating Thought 
(FEIQ), Understanding Emotions (UEIQ) and Managing Emotions (MEIQ). Scores are represented numerically, but also a score range is provided to help interpret the results. Scores between 90 and 109 are considered to indicate that the person is 'competent' in that skill area, with higher scores indicating that the person is more skilled while lower scores indicate that they should consider improving their capacity in that area.

Reliability is assessed using split-half analyses for the EIQ and four-branch scores. A score of .7 or higher is regarded as showing a reliable measure. Mayer et al. (2004, p. 201) report reliability scores of .93 for the EIQ score and between .76 and .91 for the four-branch scores. It should be noted that while the validity and reliability of the measure is strong at the level of a global score (EIQ) and at the level of the four branch scores (PEIQ; FEIQ; UEIQ; MEIQ), below the branch score level the reliability of the test is diminished (Mayer et al., 2002b) and so it is only the general score and the branch scores which are reported upon here, as in the MSCEIT literature more generally. The test-retest reliability was .86 for the MSCEIT total score after a threeweek period (Brackett \& Mayer, 2003, p. 1152).

As has been noted above, the MSCEIT can be regarded as a more valid measure of emotional intelligence than other tests because the MSCEIT actually assesses skills as opposed to a person's perception of their skills (Roberts, Zeidner, \& Matthews, 2001, p. 200). Likewise, the clear correspondence between the definition of emotional intelligence and the test structure means the test can also be regarded as having a high degree of content validity. The factorial or structural validity of the measure has been assessed using confirmatory factor analysis. This confirms that the overall EIQ score and the four branch scores are both good fits for the MSCEIT V2.0 and its predecessors (MEIS and MSCEIT V1.1; Mayer, Salovey, Caruso, \& Sitarenios, 2003, p. 104). In other words, factor analysis supports the idea that the test is measuring four different abilities which can meaningfully be clustered together to represent a single measure that is EIQ.

\subsection{Confirmatory Factor Analysis}

Confirmatory Factor Analysis (CFA) was performed using AMOS. Based on previous recommendations (Cole, 1987; Marsh, Balla, \& McDonald, 1988), the indices selected to assess goodness-of-fit were as follows: the Goodness-of-Fit Index (GFI) and the Adjusted Goodness-of-Fit Index (AGFI) (Jöreskog \& Sörbom, 1981), the Normed Fit Index (NFI) and the Non-Normed Fit Index (NNFI) (Bentler \& Bonett, 1980), and the Root Mean Squared Error of Approximation (RMSEA). The criteria used to indicate good fit, based on several evaluations (Anderson \& Gerbing, 1984; Cole, 1987; Marsh et al., 1988; McDonald \& Marsh, 1990), include the following: GFI > .85, AGFI > .80, $\mathrm{NFI}>.90$, NNFI $>.90$, and RMSEA $<.08$. Using expert scoring, the model consisting of four branch scores - Perceiving Emotions (PEIQ), Facilitating Thought (FEIQ), Understanding Emotions (UEIQ) and Managing Emotions (MEIQ) - produced highly acceptable goodness-of-fit indices $(\mathrm{GFI}=.98$, AGFI $=.96$, NFI $=.92$, NNFI $=.92$, RMSEA $=.05)$. The area level structure - scores from the four branch scores combine into two area scores - was also supported by the goodness-of-fit indicators (GFI $=1.00$, AGFI $=.98$, NFI $=.99$, NNFI $=.98$, RMSEA $=.04)$. This confirms that, in the Irish context, the four branch structure of the MSCEIT remains valid.

\subsection{Limitations}

The results presented in this paper need to be interpreted in a context of some important conceptual and methodological limitations. First, much of the existing research in the area of emotions in education is qualitative and descriptive. This makes obvious sense, 
given that meaning is central to the experience of emotion (Denzin, 1984). Recognising the dominance of qualitative approaches, Sutton and Wheatley (2003) conclude that multiple measures research is needed to gain a more complete picture of teachers' emotions. This paper does not match quantitative with qualitative data within the study; however, it clearly complements the qualitative data that are found in the literature.

Second, while the validity and reliability of the MSCEIT is well established, quantitative models for assessing emotional skills, like the MSCEIT, are not without limitations. As with any quantitative test, one must be cautious to avoid drawing overstated inferences from the scores. The MSCEIT is designed to assess the four areas of skill included in the Mayer and Salovey definition of emotional intelligence. It is not a measure of 'niceness', personal warmth or moral behaviour. It does not measure personality-type variables associated with emotion (such as emotional stability or optimism). Nor does it indicate whether or not a person is likely to use their competences in any given interaction.

Third, these data have been collected in an Irish context. As with all quantitative tests there are questions about the applicability of the MSCEIT to different ethnic or national groups. It was normed based on an expert group drawn from an international panel, with participants from a number of continents, but primarily based in the US. As such, while the test constructors have made an effort to ensure that the test is not culturally biased, it is still open to question as to whether or not the norms are genuinely transferable across different ethnic groups or national origins (Sue, 1999). The test was reviewed for cultural applicability before its use and no issues with language were reported by participants during the testing. The CFA which was carried out also indicates that the factor structure remains valid in an Irish context.

\section{Results}

\subsection{Overall scores obtained by all student teachers}

The means and standard deviations for total EIQ and each of the four skills - PEIQ, FEIQ, UEIQ and MEIQ - are reported in Table 2. The average total EIQ score for the 352 students on the MSCEIT was within the competent range, but is more than 0.5 of a standard deviation below the expected average score of 100 . The average scores for the four skills were also within the competent range and below the expected average of 100. As Table 3 shows, the students' average scores were significantly below the expected mean in the case of all four branch scores and in their overall EIQ score.

A within-subjects analysis of variance (ANOVA) permitted determination of whether individuals differed with respect to the four branch scores. Mauchly's test indicated that the assumption of sphericity had been met $\left(\chi^{2}(5)=7.68, p>.05\right)$. Results indicated that student teachers differed significantly with respect to each of the four branch scores, $F(3,1053)=9.19,(p<.0001)$. Post-hoc comparisons were employed to determine the nature of these differences and the results are reported in Table 4.

Table 2: Means and standard deviations for total EIQ and branch scores $(\mathrm{N}=352)$

\begin{tabular}{lcc}
\hline Skill & $M$ & $S D$ \\
\hline PEIQ & 94.30 & 13.43 \\
FEIQ & 97.23 & 15.95 \\
UEIQ & 93.76 & 12.02 \\
MEIQ & 97.50 & 14.20 \\
EIQ & 92.18 & 12.92 \\
\hline
\end{tabular}


Table 3: One-sample t-test comparing mean scores for each of the four EI skills attained by all participants with the average score for the population (Test Value $=$ 100)

\begin{tabular}{lcccccc}
\hline & $t$ & $d f$ & $\begin{array}{c}\text { Sig. (2- } \\
\text { tailed) }\end{array}$ & Mean Diff & \multicolumn{2}{c}{$95 \%$ CI } \\
\cline { 6 - 7 } & & & & Lower & Upper \\
\hline PEIQ & $-7.96^{* *}$ & 351 & .000 & -5.70 & -7.11 & -4.29 \\
FEIQ & $-3.25^{* *}$ & 351 & .001 & -2.77 & -4.44 & -1.09 \\
UEIQ & $-9.74^{* *}$ & 351 & .000 & -6.24 & -7.50 & -4.98 \\
MEIQ & $-3.30^{* *}$ & 351 & .001 & -2.50 & -3.99 & -1.01 \\
EIQ & $-11.35^{* *}$ & 351 & .000 & -7.82 & -9.17 & -6.46 \\
\hline${ }^{*}<.05 .{ }^{* *} p<.01$. & & & & & &
\end{tabular}

Table 4: Post-hoc comparisons

\begin{tabular}{lccccc}
\hline Skill & Mean Diff & $\begin{array}{c}\text { Std. Error } \\
\text { Diff }\end{array}$ & Sig. & \multicolumn{2}{c}{ 95\% CI } \\
\cline { 5 - 6 } & & & Lower & Upper \\
\hline FEIQ PEIQ & $2.94^{* *}$ & .88 & .006 & 0.60 & 5.27 \\
FEIQ UEIQ & $3.47^{* *}$ & .95 & .002 & 0.96 & 5.99 \\
MEIQ PEIQ & $3.20^{* *}$ & .91 & .003 & 0.80 & 5.61 \\
MEIQ UEIQ & $3.47^{* *}$ & .86 & .000 & 1.47 & 6.02 \\
${ }^{*} p<.05 .{ }^{* *} p<.01$. & & & &
\end{tabular}

\subsection{Differences between undergraduate and graduates in the sample}

Despite the differences between the entry and qualifications of the undergraduate and graduate elements of the sample, there are very little differences between the scores obtained by students in undergraduate and graduate diploma courses; the means and standard deviations are reported in Table 5. It is notable that, contrary to what one might have expected, the score for graduates (who are on programs that require both high academic attainment and an interview for entry) is actually lower than the undergraduates scores (who enter on the basis of academic achievement alone) for EIQ, PEIQ and MEIQ. The two group means for total EIQ and each of the four EI skills are compared using independent samples t-tests (results of Levene's test for equality of variances indicates equal variances may be assumed for both groups in each test). The difference (3.49) is only significant for PEIQ at the .05 level, $t(350)=2.43, p<.05$, $95 \%$ CI $[0.67,6.30]$. This indicates the mean score for the 'perceiving emotions' skill area is statistically significantly higher for undergraduate students than graduate students.

Table 5: Means and standard deviations for total EIQ and branch scores based on undergraduate and graduate diploma courses

\begin{tabular}{lccccc}
\hline Skill & \multicolumn{2}{c}{ Undergraduate } & & \multicolumn{2}{c}{ Graduate } \\
\cline { 2 - 3 } \cline { 5 - 6 } & $M$ & $S D$ & & $M$ & $S D$ \\
\hline PEIQ & 95.83 & 13.34 & & 92.35 & 13.35 \\
FEIQ & 96.32 & 15.47 & & 98.40 & 16.51 \\
UEIQ & 93.09 & 11.74 & & 94.62 & 12.35 \\
MEIQ & 97.66 & 13.24 & & 97.30 & 15.38 \\
EIQ & 92.52 & 12.36 & & 91.76 & 13.62 \\
\hline
\end{tabular}

4.3 Differences between male and female students 
There are differences in the mean scores obtained by male and female students within the sample, the means and standard deviations are reported in Table 6. Results indicate that the mean scores for female student teachers are higher across all skill areas. Independent samples t-tests indicate that the mean scores for males for each of the EI skills are statistically significantly lower than the mean scores for females; results are reported in Table 7.

Table 6: Means and standard deviations for total EIQ and branch scores based on gender

\begin{tabular}{lccccc}
\hline Skill & \multicolumn{2}{c}{ Female } & & \multicolumn{2}{c}{ Male } \\
\cline { 2 - 3 } \cline { 5 - 6 } & $\mathrm{M}$ & $\mathrm{SD}$ & & $\mathrm{M}$ & $\mathrm{SD}$ \\
\hline PEIQ & 95.52 & 13.24 & & 92.60 & 13.56 \\
FEIQ & 100.18 & 14.78 & & 93.13 & 16.64 \\
UEIQ & 94.99 & 11.88 & & 92.05 & 12.05 \\
MEIQ & 100.27 & 14.23 & & 93.65 & 13.28 \\
EIQ & 94.76 & 12.67 & & 88.60 & 12.44 \\
\hline
\end{tabular}

Table 7: Independent samples t-tests for total EIQ and branch scores based on gender

\begin{tabular}{|c|c|c|c|c|c|}
\hline \multirow[t]{2}{*}{ Skill } & \multirow[t]{2}{*}{$t$} & \multirow[t]{2}{*}{$d f$} & \multirow[t]{2}{*}{ Sig. } & \multicolumn{2}{|c|}{$95 \%$ CI } \\
\hline & & & & LB & UB \\
\hline PEIQ & $2.02^{*}$ & 350 & .044 & 0.08 & 5.77 \\
\hline FEIQ & $4.19^{* *}$ & 350 & .000 & 3.74 & 10.37 \\
\hline UEIQ & $2.27^{*}$ & 350 & .024 & 0.39 & 5.47 \\
\hline MEIQ & $4.42^{* *}$ & 350 & .000 & 3.67 & 9.56 \\
\hline EIQ & $4.53^{* *}$ & 350 & .000 & 3.49 & 8.83 \\
\hline
\end{tabular}

Given that the student's course of study was related to their gender (with male students more likely to be studying to be engineering, or technology teachers and female students more likely to be studying to be language, music, PE or science teachers) it is worth questioning how this 'gender effect' relates to their course of study. Indeed, there were differences between the scores of students depending on their course of study (data not presented due to space constraints and as they are not crucial to the argument presented here). A two-way independent ANOVA was used to examine the interaction between gender and school subjects. Results indicate a significant main effect (at the $p$ $=.05$ level) for gender on EIQ, controlling for school subjects, is found, $F(1,336)=$ $6.52, p=.011$. The effect for school subjects on EIQ, controlling for gender, was found to be notable, but not significant, $F(8,336)=1.78, p=.08$. A non-significant interaction effect between college course and gender on EIQ is found, $F(6,336)=1.87, p=.086$. A significant main effect for gender on FEIQ, controlling for school subjects, is also found, $F(1,336)=8.07, p=.005$.

\section{Discussion}

The evidence highlighted earlier suggests that having a high level of emotional competence is likely to be of positive benefit to teachers and their pupils. The few studies that exist on this topic show contradictory findings as to whether student teachers' levels of emotional intelligence are broadly in line with expected averages (Byron, 2001) or below average (Brackett et al., 2010; Corcoran \& Tormey, 2011, in press). This study, based on a reasonably large data set, shows that the pre-service 
student teachers studied have levels of emotional intelligence below the norm for the wider population. If anything, the evidence here is even more stark than in other studies, with the mean average score for the sample of student teachers being more than 0.5 of a standard deviation below the average for the wider population, and, for male student teachers, being 0.8 of a standard deviation below the average for the wider population - below the range that is described as 'competent'. The gender differences are greater in this sample than would be expected in the wider population (Mayer et al., 2002b, p. 32). The pattern of student scores on each of the four components is also associated with gender: female students perform about average at using emotion to facilitate thinking and at regulation of emotion, but less well in the other two components. Male students perform about the same (92 or 93 on average) in all four skill areas. As was noted above, the emotional skills of teachers have been found to influence student conduct, engagement, attachment to school, and academic performance (Baker, 1999; Hawkins, 1999; Schaps et al., 1996; Wentzel, 2002). It is therefore a cause for some concern that student teachers on average show such low levels of emotional intelligence.

As was noted above, one response to this finding might be to look to alternative entry routes into teacher education which are based in part on "personal suitability data" (Coolahan, 2003, p. 22). The data here would not suggest that interviewing students is an appropriate way of achieving this. It is notable that the comparatively low levels of EI for student teachers holds true irrespective of whether the student teachers in question are on a graduate program (in which acceptance on the program requires both high academic attainment and a strong performance at interview) or an undergraduate program (in which acceptance on the program is based only on high academic attainment). Given the frequent international debate concerning entry routes to teacher education programs, these are important findings.

Given the comparatively low levels of emotional intelligence found among student teachers it is worth considering including a focus on such emotional competences within pre-service teacher education programmes. Again, the data is helpful here as it highlights the skill areas that are in need of most attention. The Mayer and Salovey model of emotional intelligence identifies four skill areas, and each of them will now be looked at in turn. The first skill area was the perception, appraisal, and expression of emotion (PEIQ). This area has frequently been identified as important for teachers and as Whitcomb et al. (2008, p. 269) have commented: "A quality of attentiveness to both our selves and our students is central". Because the MSCEIT is a test of emotional skills "in abstract" rather than in specific teaching situations it is not possible to be too precise as to how a low level of skill in any of the four areas would be evident in a teacher's work, however a low level of skill in this area might be likely to be seen in a teacher failing to recognise their own emotional state and the way it is impacting upon their behaviour. It may also mean that they have a decreased sense of being in control of their own emotions. It is likely to mean a teacher who has trouble in picking up on emotional cues which might alert them to students who are bored, frustrated, angry, excited and so on. This is likely to impact upon both learning and on the social and behavioural environment in the classroom. The evidence here is that student teachers in this study were, on average, within the competent range, but were significantly below the expected average in this area (Table 3), and were worse at this than at a number of other skill areas (Table 4). Despite the fact that the graduate students had all been chosen through interviews, and the undergraduates had not, the undergraduates actually outperformed the graduates on this competence (Table 5). Male students did worse than female students on this area of skill (Table 7) although 
the gap between them was not as large as in other skill areas. How can student teachers develop their capacity to recognise emotions in self and others? Activities such as asking students to identify their own emotional state and how and where they feel that emotion in their body can begin to raise awareness of their own emotional state and its physical impact upon them. This can be combined with an emotional diary activity that can ask them to note what emotion(s) they are feeling at different times in the day or week and how they experience that emotion physiologically (Caruso \& Salovey, 2004, p. 92). By sharing such diary entries with each other, students may start to broaden their awareness of emotions in other people. Engaging in and debriefing each other when involved in role-playing activities in which they seek to act out non-verbally a particular emotional response to a scenario may also be valuable activities to help develop this skill area. The role of meditation in aiding an awareness of emotions has been highlighted (Whitcomb et al., 2008), while Hoekstra and Korthagen (2011) have highlighted that feedback to teachers on the emotions they appear to be displaying in a coaching context can aid the awareness of emotions.

The second skill area was using emotions to facilitate thinking (FEIQ). Skills in this area are likely to be important in enabling the kind of emotional scaffolding that Rosiek (2003) identifies as an important part of teachers' pedagogic content knowledge. This skill area also involves the ability to generate emotions required to facilitate particular thinking activities. While the students teachers in this study were, on average, significantly below the expected mean score of 100 they were significantly stronger in this area than in perceiving emotions and in understanding emotional changes (Table 4); this is largely attributable to the fact that the average score for female students for this skill was at the population average, however, the score for male students remained notably lower. This is the skill area which saw the largest gap between the performance of male and female students. How might this ability be developed in student teachers? For student teachers, an awareness of the different types of thinking activities that contribute to learning (Krathwohl, 2002) are probably already addressed in their programs. In doing this it would also be possible to broaden this to include a focus on how different sorts of emotions can facilitate or hinder different types of thinking (Isen, et al., 1987; Palfai \& Salovey, 1993). Caruso and Salovey (2004, p. 110) suggest that people can also learn to generate emotions through linking into past emotional memories and through using techniques used in drama to develop what they refer to as their "emotional imagination."

The third skill area is understanding and analysing emotional information (UEIQ). Given the characterisation of the student teacher experience as a whirlpool of ever changing emotions (Erb, 2002) and of the classroom as an emotionally dynamic space in which different emotions are always ebbing and flowing (Intrator, 2006) it would seem that an understanding of how a given emotion is likely to change in response to different events would be an important ability for student teachers. As with perceiving emotions, however, this is an area of comparative weakness for the student teachers. This was the area in which they scored lowest of all (Table 3), and their scores on this area was statistically significantly lower than for using emotions to facilitate thinking and for managing emotional regulation (Table 4). Again, male student teachers scored lower than female student teachers and this difference is statistically significant. How might student teachers develop their abilities in this area? The Plutchik Circumplex (Plutchik, 1994, 2001) is a useful framework for enabling student teachers to begin to conceptualise the intensification of emotions as well as for developing their emotional vocabulary - something which is seen to be associated with this skill area (Caruso \& Salovey, 2004, p. 123). Role plays and scenario work in which 
they are asked to enact or discuss what emotions are likely to be experienced in a given situation and how a new event may affect those emotions may also be a valuable learning experience.

The fourth skill area is the regulation of emotion (MEIQ); according to Koole (2009, p. 5), the "tremendous increase in research volume has rendered the study of emotion regulation one of the most vibrant areas in contemporary psychology". Hargreaves (1998, 2000) draws on Hochschild's concept of emotional labour to describe the processes for teachers in regulating their emotional displays with both pupils and with parents, although the regulation of emotion goes beyond regulating what emotion you show (Gross, 1998a, 1998b; Gross \& Thompson, 2007). Emotion regulation involves applying the evaluation process to emotion itself and may be located in the regulator (teachers' may try to calm themselves down, for example) or may involve extrinsic regulation, that is, the regulation of the emotions of others' (teachers' may try to calm their students down, for example). It has been argued, for example, that the culture of teaching requires or should require teachers to care (Noddings, 1992) and to have passion (Fried, 1995) love, sympathy, concern (Oplatka, 2007). One important aspect of emotion regulation for teachers is working with stress. The stress that teachers experience has been recognised as an international phenomenon, with studies on teacher stress having been conducted in Canada (Klassen, 2010), France (Pedrabissi, Rolland, \& Santinello, 1993), Italy (Pisanti, Gagliardi, Razzino, \& Bertini, 2003), the Netherlands (de Heus \& Diekstra, 1999), China (Hui \& Chan, 1996), Australia (Pithers \& Soden, 1998), and many other developed countries (Boyle et al., 1995; Kyriacou, 1987, 1998; van Dick \& Wagner, 2001). In one study, Travers and Cooper (1993) found that more than thirty percent of British teachers perceived their jobs as stressful with reports of increasing pressure. While Borg (1990) found about as many as a third of the teachers surveyed in various studies around the world reported that they regarded teaching as highly-stressful. Stress and negative affect interfere with self-regulation (Holm-Denoma, Joiner, Vohs, \& Heatherton, 2008; Keel, Baxter, Heatherton, \& Joiner, 2007; Sinha, 2007; Sinha et al., 2008). Self-regulatory failure is a core feature of many social and mental health problems (DeWall et al., 2011; Gruber, Harvey, \& Gross, in press; Gyurak, Gross, \& Etkin, 2011; Heatherton, 2011; Heatherton \& Wagner, 2011; Kober \& Ochsner, in press; Williams, Bargh, Nocera, \& Gray, 2009). It is therefore not surprising that stress and poor emotion management continually rank as the primary reasons why teachers become dissatisfied with the profession and end up leaving their positions (Darling-Hammond, 2001). Teachers' with high emotion regulation scores (MEIQ) tend to report less burnout and job satisfaction; they also experience greater positive affect while teaching and receive more support from the principals with whom they work (Brackett et al., 2010). Although the average MEIQ for the student teachers was significantly below the expected average (Table 3), this was an area of comparative strength for them; their score on this area was significantly higher than their score for perceiving emotions and for understanding emotions (Table 4). Again, as was the case with using emotions, this can be attributed to the fact that the average score for female students was almost half (0.44) of a standard deviation higher than the score for male students. There were no notable differences between undergraduate and graduate students on this skill. This skill area involves allowing oneself to be open to emotions and to use the information that emotions convey in a judicious way. How can student teachers develop their skills in this area? The regulation of emotion involves the use of strategies such as a person acting upon or changing their own physiological state, as well as the use of cognitive strategies (Caruso \& Salovey, 2004, pp. 134-155). Student teachers can learn to better regulate their emotions using a range of strategies including 
cognitive reframing of a situation, relaxation techniques, reflection or visualization, for example (for further discussion see Corcoran \& Tormey, in press). Evidence suggests that having a range of strategies is important because some strategies are more helpful in particular situations than others and there is no one strategy that works always. For example, aggregated evidence suggests that suppression is cognitively and socially costly (Butler et al., 2003; Gross, 2002; Srivastava, Tamir, McGonigal, John, \& Gross, 2009), while reappraisal can be helpful in particular situations because the individual is deeply processing information (Gross \& John, 2003; Mauss, Cook, Cheng, \& Gross, 2007; McRae, Heller, John, \& Gross, 2011; Richards \& Gross, 2000). However, which strategy is preferentially engaged switches from predominantly reappraisal at the lower emotion intensity to predominantly distraction at the higher intensity (Sheppes, Scheibe, Suri, \& Gross, 2011). In addition, the effectiveness of reappraisal is moderated by emotion intensity where distraction is not. Also distraction may be more difficult to self generate in a contextually sensitive fashion and reappraisal may be able to be cued more appropriately in particular contexts than distraction which is cued very early in the emotion regulation process (Sheppes \& Gross, in press; Suri, Sheppes, \& Gross, in press). These findings suggest that which strategy works best varies as a function of context, one dimension of which is emotion intensity (Sheppes \& Gross, 2011). Therefore, it is important to teach teachers and student teachers to have a richer array of regulatory processes so they can flexibly implement them in a situation specific fashion. This also means that student teachers must be taught to think about the match between the strategy and the situation/context in order to effectively regulate their own and other's emotions. Indeed, there is now a very solid evidence base to support the view that such skills can be learned and effectively used (Sheldon, 2011), including recent research using functional magnetic resonance imaging (fMRI) methods which suggests that specific strategies (namely re-interpretation of the external world vs. distancing oneself from it) may be differentially susceptible to training (Ochsner, 2011).

It is worth reflecting a little on the gendered nature of the data presented here. In this study male students scored on average lower than female students though again, the ranges in scores means that there are many males which have higher levels of emotional intelligence than many females. The gender differences in this sample were wider than those in the normative sample used for the MSCEIT. It may be that this is in part a function of the particularly gendered culture of the subjects which the students were preparing to teach (with male student teachers largely drawn from the engineering construction and technology programs and female students largely drawn from physical education, science, languages, music and business programs) - there was a notable if marginally non-significant effect for school subjects when gender was controlled for. Over and above that, it may also reflect a cultural difference in gendering of emotional skills between the Irish and US samples (a significant effect for gender remained when school subject was controlled for). This suggests that it is worth thinking about emotional skills not only as a skill of the individual, but as something which may well be woven into gendered and subject-specific social expectations.

The data presented here, drawn from a relatively large study of emotional intelligence in pre-service teacher education suggests that student teachers may have comparatively low levels of emotional intelligence (though of course, the range of scores means that some will have levels which are above the expected average for the wider population). While there is an active debate on whether personal suitability data can effectively complement academic factors in entry into teacher education, the evidence presented here does not support the contention that using interview data to supplement academic data makes a difference to the emotional intelligence of the 
teacher candidates admitted. The data presented here refers to the emotional skills of student teachers measured in abstract, and does not allow for clear statements to be made about how they use these abstract skills in the situated reality of classroom life. This may mean a need to develop context-specific versions of the test (Corcoran \& Tormey, 2011). At the same time, there are clear grounds for suggesting that pre-service teacher education should pay attention to developing emotional competences in student teachers. The data presented here suggests that for many students all four skill areas will be important, but that (a) perceiving emotions in self and others and (b) understanding and analysing emotional information may be particularly weak areas for many student teachers.

\section{Conclusion}

Emotions matter in learning, in teaching and in learning to teach. If student teachers are to develop the emotional competence that might allow them to work with the emotional dimensions of pupil learning - and the emotional dimensions of their own process of learning to teach - then we need a conceptual framework which would allow us to identify particular sets of necessary skills and to put in place activities which would enable learners to develop and utilize that competence. Given that stress and poor emotion management continually rank as the primary reasons why teachers become dissatisfied with the profession and end up leaving their positions (DarlingHammond, 2001), and given that social and emotional skills are associated with success in many areas of life, including teaching, student learning, quality relationships, and academic performance (Durlak et al., 2011) the case for a focus on development of emotional competences in pre-service teacher education seems very strong (Palomera, Fernandez-Berrocal, \& Brackett, 2008; Weare \& Gray, 2003).

The evidence here suggests that, on average, student teachers may need help in all four of the competence areas that we have described, however it does also suggest that teacher education programs might need to place a particular emphasis on the skills of perceiving emotions in self and others, and of understanding emotional changes and progressions. The data also suggests that male students, on average, are weaker than female students at using emotions to facilitate thinking and at regulation of emotion (though such averages should not obscure the variances in scores in both male and female students). This finding directs attention to the way in which emotional skills are developed in and embedded in gendered social experiences and possibly also in subcultures of particular school subjects. This highlights the need to see these emotional skills as embedded in social contexts. Hargreaves (1998) warns that emotional experiences are intrinsically social, and that a focus on "skills" can distract from the contextual and social dimensions of emotional experiences. However, this research suggests that the answer is not to refuse to conceptualise emotions in terms of skills or competence, but instead to see a focus on emotional intelligence as a useful counterpart to qualitative research which describes the range, depth and experience of emotions in institutional and social contexts. A general model of teacher emotions will not be framed in either/ or term, but rather in terms of both. An emotional intelligence framework does not offer a general theory of teacher emotions, and it does not address the social, institutional, cultural and labour process dimensions of teacher emotions. It does, however, offer a framework for making sense of what emotional competence teachers and student teachers need, for assessing to what extent they have required skills and for using that information in designing and reforming teacher education programs, and, at the moment, that is precisely what we need. 


\section{References}

Anderson, J. C., \& Gerbing, D. W. (1984). The effect of sampling error on convergence, improper solutions, and goodness-of-fit indices for maximum likelihood confirmatory factor analysis. Psychometrika, 49, 155-173.

Baker, J. A. (1999). Teacher-student interaction in urban at-risk classrooms: Differential behavior, relationship quality, and student satisfaction with school. The Elementary School Journal, 100, 57-70.

Bar-On, R. (1997a). Bar-On Emotional Quotient Inventory (EQ-i): A test of emotional intelligence. Toronto, Canada: Multi-Health Systems.

Bar-On, R. (1997b). Bar-On Emotional Quotient Inventory (EQ-i): Technical manual. Toronto, Canada: Multi-Health Systems.

Barrett, L. F., Robin, L., Pietromonaco, P. R., \& Eyssell, K. M. (1998). Are women the "more emotional” sex? Evidence from emotional experiences in social context. Cognition \& Emotion, 12, 555578.

Bentler, P. M., \& Bonett, D. G. (1980). Significance tests and goodness of fit in the analysis of covariance structures. Psychological Bulletin, 88, 588-606.

Borg, M. G. (1990). Occupational stress in British educational settings: A review. Educational Psychology: An International Journal of Experimental Educational Psychology, 10, 103-126.

Boyatzis, R. E., Goleman, D., \& Hay/McBer. (1999). Emotional competence inventory. Boston: HayGroup.

Boyatzis, R. E., Goleman, D., \& Rhee, K. S. (2000). Clustering competence in emotional intelligence. In R. Bar-On \& J. D. A. Parker (Eds.), The handbook of emotional intelligence: Theory, development, assessment, and application at home, school, and in the workplace. San Francisco, California: Jossey-Bass.

Boyle, G. J., Borg, M. G., Falzon, J. M., \& Baglioni, A. J. (1995). A structural model of the dimensions of teacher stress. British Journal of Educational Psychology, 65, 49-67.

Brackett, M. A., \& Mayer, J. D. (2003). Convergent, discriminant, and incremental validity of competing measures of emotional intelligence. Personality and Social Psychology Bulletin, 29, 1147-1158.

Brackett, M. A., Mayer, J. D., \& Warner, R. M. (2004). Emotional intelligence and its relation to everyday behaviour. Personality and Individual Differences, 36, 1387-1402.

Brackett, M. A., Palomera, R., Mojsa-Kaja, J., Reyes, M. R., \& Salovey, P. (2010). Emotion-regulation ability, burnout, and job satisfaction among British secondary-school teachers. Psychology in the Schools, 47, 406-417.

Briton, N. J., \& Hall, J. A. (1995). Beliefs about female and male nonverbal communication. Sex Roles, 32, 79-90.

Brody, L. R., \& Hall, J. A. (2000). Gender emotion and expression. In M. J. Lewis \& J. M. HavilandJones (Eds.), Handbook of emotions (second ed., pp. 338-349). New York: Guilford Press.

Bullough, R. V., Knowles, J. G., \& Crow, N. A. (1991). Emerging as a teacher. London; New York: Routledge.

Butler, E. A., Egloff, B., Wlhelm, F. H., Smith, N. C., Erickson, E. A., \& Gross, J. J. (2003). The social consequences of expressive suppression. Emotion, 3, 48-67.

Byron, C. M. (2001). The effects of emotional knowledge education in the training of novice teachers. Unpublished Doctoral thesis, Teachers College, Columbia University, New York. Available from ProQuest Dissertations and Thesis database (UMI No. 3014883).

Caruso, D. R., \& Salovey, P. (2004). The emotionally intelligent manager: How to develop and use the four key emotional skills of leadership (first ed.). San Francisco, California: Jossey-Bass.

Coats, E. J., \& Feldman, R. S. (1996). Gender differences in nonverbal correlates of social status. Personality and Social Psychology Bulletin, 22, 1014-1022.

Cochran-Smith, M., \& Fries, K. (2006). The AERA panel on research and teacher education: Context and goals. In M. Cochran-Smith \& K. M. Zeichner (Eds.), Studying teacher education: The report of the AERA panel on research and teacher education (pp. 37-68). Mahwah, New Jersey: Lawrence Erlbaum Associates.

Cole, D. A. (1987). Utility of confirmatory factor analysis in test validation research. Journal of Consulting and Clinical Psychology, 55, 584-594.

Conway, P. F., Murphy, R., Rath, A., \& Hall, K. (2009). Learning to teach and its implications for the continuum of teacher education: A nine-country cross-national study. Maynooth, Ireland: The Teaching Council. 
Coolahan, J. (2003). Attracting, developing and retaining effective teachers: Country background report for Ireland. Dublin: Stationery Office.

Corcoran, R. P. (2011). Investigating the role of emotional competencies in initial teacher education. Unpublished Doctoral Dissertation, University of Limerick, Ireland.

Corcoran, R. P., \& Tormey, R. (2010). Teacher education, emotional competencies and development education. Procedia - Social and Behavioral Sciences, 2, 2448-2457.

Corcoran, R. P., \& Tormey, R. (2011). Assessing emotional intelligence and its impact in caring professions: The value of a mixed methods approach in emotional intelligence work with teachers. In A. Di Fabio (Ed.), Emotional Intelligence: InTech Publishing.

Corcoran, R. P., \& Tormey, R. (in press). Developing emotionally competent teachers: Emotional intelligence and pre-service teacher education. U.K.: Peter Lang Publishing.

Darling-Hammond, L. (2001). The challenge of staffing our schools. Educational Leadership, 58, 12-17.

de Heus, P., \& Diekstra, R. F. W. (1999). Do teachers burn out more easily? A comparison of teachers with other social professions on work stress and burnout symptoms. In R. Vandenberghe \& A. M. Huberman (Eds.), Understanding and preventing teacher burnout: A sourcebook of international research and practice (pp. 269-284): New York, US: Cambridge University Press.

Denzin, N. K. (1984). On Understanding Emotion. London: McGraw-Hill.

DeWall, C. N., Twenge, J. M., Koole, S. L., Baumeister, R. F., Marquez, A., \& Reid, M. W. (2011). Automatic emotion regulation after social exclusion: Tuning to positivity. Emotion, 11, 623636.

Dimberg, U., \& Lundquist, L. (1990). Gender differences in facial reactions to facial expressions. Biological Psychology, 30, 151-159.

Duckworth, A. L., Kirby, T. A., Gollwitzer, A., \& Oettingen, G. (in press). Teaching self-regulation improves academic performance.

Dunning, D., Heath, C., \& Suls, J. M. (2004). Flawed self-assessment: Implications for health, education, and the workplace. Psychological Science in the Public Interest, 5, 69-106.

Durlak, J. A., Weissberg, R. P., Dymnicki, A. B., Taylor, R. D., \& Schellinger, K. B. (2011). The impact of enhancing students' social and emotional learning: A meta-analysis of school-based universal interventions. Child Development, 82, 405-432.

Emmer, E. T. (1994). Towards an understanding of the primacy of classroom management and discipline. Teaching Education, 6, 65-69.

Erb, C. S. (2002, May) The emotional whirlpool of beginning teachers' work, Paper presented at the annual meeting of the Canadian Society of Studies in Education, Toronto, Canada.

Evelein, F., Korthagen, F., \& Brekelmans, M. (2008). Fulfilment of the basic psychological needs of student teachers during their first teaching experiences. Teaching and Teacher Education, 24, 1137-1148.

Fischer, A. H., \& Manstead, A. (2000). The relation between gender and emotions in different cultures. In A. H. Fischer (Ed.), Gender and emotion: Social psychological perspectives (pp. 71-94). Cambridge, England: Cambridge University Press.

Fried, R. L. (1995). The passionate teacher: A practical guide. Boston: Beacon Press.

Goleman, D. (1995). Emotional intelligence: Why it can matter more than IQ. New York: Bantam Books.

Gross, J. J. (1998a). The emerging field of emotion regulation: An integrative review. Review of General Psychology, 2, 271-299.

Gross, J. J. (1998b). Antecedent- and response-focused emotion regulation: Divergent consequences for experience, expression, and physiology. Journal of Personality and Social Psychology, 74, 224237.

Gross, J. J. (2002). Emotion regulation: Affective, cognitive, and social consequences. Psychophysiology, 39, 281.

Gross, J. J., \& John, O. P. (2003). Individual differences in two emotion regulation processes: Implications for affect, relationships, and well-being. Journal of Personality and Social Psychology, 85, 348-362.

Gross, J. J., \& Thompson, R. A. (2007). Emotion regulation: Conceptual foundations. In J. J. Gross (Ed.), Handbook of emotion regulation (pp. 3-24). New York; London: Guilford.

Gruber, J., Harvey, A. G., \& Gross, J. J. (in press). When trying is not enough: Emotion regulation and the effort-success gap in bipolar disorder. Emotion.

Gyurak, A., Gross, J. J., \& Etkin, A. (2011). Explicit and implicit emotion regulation: A dual-process framework. Cognition and Emotion, 25, 400-412.

Hargreaves, A. (1998). The emotional practice of teaching. Teaching and Teacher Education, 14, 835854. 
Hargreaves, A. (2000). Mixed emotions: Teachers' perceptions of their interactions with students. Teaching and Teacher Education, 16, 811-826.

Hawkins, J. D. (1999). Academic performance and school success: Sources and consequences. In R. P. Weissberg, T. P. Gullotta, R. L. Hampton, B. A. Ryan \& G. R. Adams (Eds.), Enhancing children's wellness (pp. 276-305). Thousand Oaks, CA: Sage.

Heatherton, T. F. (2011). Neuroscience of self and self-regulation. Annual Review of Psychology, 62, 363-390.

Heatherton, T. F., \& Wagner, D. D. (2011). Cognitive neuroscience of self-regulation failure. Trends in Cognitive Sciences, 15, 132-139.

Helsing, D. (2007). Regarding uncertainty in teachers and teaching. Teaching and Teacher Education, 23, 1317-1333.

Hochschild, A. R. (2003). The managed heart: Commercialization of human feeling, 20th Anniversary Edition (20th anniversary ed.). Berkley: University of California Press.

Hoekstra, A., \& Korthagen, F. (2011). Teacher learning in a context of educational change: Informal learning versus systematically supported learning. Journal of Teacher Education, 62, 76-92.

Holm-Denoma, J. M., Joiner, T. E., Vohs, K. D., \& Heatherton, T. F. (2008). The "freshman fifteen" (the" freshman five" actually): Predictors and possible explanations. Health Psychology, 27, S3S9.

Hui, E. K. P., \& Chan, D. W. (1996). Teacher stress and guidance work in Hong Kong secondary school teachers. British Journal of Guidance and Counselling, 24, 199-211.

Humphrey, N., Curran, A., Morris, E., Farrell, P., \& Woods, K. (2007). Emotional intelligence and education: A critical review. Educational Psychology, 27, 235-254.

Intrator, S. M. (2006). Beginning teachers and the emotional drama of the classroom. Journal of Teacher Education, 57, 232-239.

Isen, A. M., Daubman, K. A., \& Nowicki, G. P. (1987). Positive affect facilitates creative problem solving. Journal of Personality and Social Psychology, 52, 1122-1131.

Jennings, P. A., \& Greenberg, M. T. (2008). The prosocial classroom: Teacher social and emotional competence in relation to student and classroom outcomes. Review of Educational Research, 79, 491.

Jöreskog, K. G., \& Sörbom, D. (1981). LISREL VI: Analysis of linear structural relationships by maximum likelihood, instrumental variables, and least squares methods. Mooresville, IN: Scientific Software.

Keel, P. K., Baxter, M. G., Heatherton, T. F., \& Joiner, T. E. (2007). A 20-year longitudinal study of body weight, dieting, and eating disorder symptoms. Journal of Abnormal Psychology, 116, 422-432.

Klassen, R. M. (2010). Teacher stress: The mediating role of collective efficacy beliefs. The Journal of educational research, 103, 342.

Kober, H., \& Ochsner, K. N. (in press). Regulation of emotion in major depressive disorder. Biological psychiatry.

Koole, S. L. (2009). The psychology of emotion regulation: An integrative review. Cognition and Emotion, 23, 4-41.

Krathwohl, D. R. (2002). A revision of Bloom's taxonomy: An overview. Theory into practice, 41, 212218.

Kyriacou, C. (1987). Teacher stress and burnout: An international review. Educational Research, 29, 146-152.

Kyriacou, C. (1998). Teacher stress: Past and present. In J. Dunham \& V. Varma (Eds.), Stress in teachers: Past, present and future (pp. 1-13). London: Whurr.

Lopes, P. N., Brackett, M. A., Nezlek, J. B., Schütz, A., Sellin, I., \& Salovey, P. (2004). Emotional Intelligence and Social Interaction. Personality and Social Psychology Bulletin, 30, 1018-1034.

Lortie, D. C. (1975). School teacher: A sociological study. Chicago: University of Chicago Press.

Marsh, H. W., Balla, J. R., \& McDonald, R. P. (1988). Goodness-of-fit indexes in confirmatory factor analysis: The effect of sample size. Psychological Bulletin, 103, 391-410.

Mauss, I. B., Cook, C. L., Cheng, J. Y. J., \& Gross, J. J. (2007). Individual differences in cognitive reappraisal: Experiential and physiological responses to an anger provocation. International Journal of Psychophysiology, 66, 116-124.

Mayer, J. D., Roberts, R. D., \& Barsade, S. G. (2008). Human Abilities: Emotional Intelligence. Annual Review of Psychology, 59, 507-536.

Mayer, J. D., \& Salovey, P. (1997). What is emotional intelligence? . In P. Salovey \& D. Sluyter (Eds.), Emotional development and emotional intelligence: Educational implications (pp. 3-31). New York: Basic Books. 
Mayer, J. D., Salovey, P., \& Caruso, D. R. (2002a). The Mayer-Salovey-Caruso Emotional Intelligence Test (MSCEIT): Item booklet. Toronto, Canada: Multi-Health Systems.

Mayer, J. D., Salovey, P., \& Caruso, D. R. (2002b). The Mayer-Salovey-Caruso Emotional Intelligence Test (MSCEIT): User's manual. Toronto, Canada: Multi-Health Systems.

Mayer, J. D., Salovey, P., \& Caruso, D. R. (2004). Emotional intelligence: Theory, findings, and implications. Psychological Inquiry, 15, 197-215.

Mayer, J. D., Salovey, P., Caruso, D. R., \& Sitarenios, G. (2003). Measuring emotional intelligence with the MSCEIT V2.0. Emotion, 3, 97-105.

McDonald, R. P., \& Marsh, H. W. (1990). Choosing a multivariate model: Noncentrality and goodness of fit. Psychological Bulletin, 107, 247-255.

McRae, K., Heller, S. M., John, O. P., \& Gross, J. J. (2011). Context-dependent emotion regulation: Suppression and reappraisal at the burning man festival. Basic and Applied Social Psychology, 33, 346-350.

Meyer, D. K. (2009). Entering the emotional practices of teaching. In P. A. Schutz \& M. Zembylas (Eds.), Advances in teacher emotion research (pp. 73-91). New York: Springer.

Neisser, U., Boodoo, G., Bouchard, T. J., Boykin, A. W., Brody, N., Ceci, S. J., Halpern, D. F., Loehlin, J. C., Perloff, R., Sternberg, R. J., \& Urbina, S. (1996). Intelligence: Knowns and unknowns. American Psychologist, 51, 77-101.

Nias, J. (1996). Thinking about feeling: The emotions in teaching. Cambridge Journal of Education, 26, 293-306.

Noddings, N. (1992). The challenge to care in schools: An alternative approach to education. New York; London: Teachers College Press.

O'Connor, K. E. (2008). "You choose to care": Teachers, emotions and professional identity. Teaching and Teacher Education, 24, 117-126.

O'Connor, R. M., \& Little, I. S. (2003). Revisiting the predictive validity of emotional intelligence: Selfreport versus ability-based measures. Personality and Individual Differences, 35, 1893-1902.

Ochsner, K. (2011, November) The cognitive control of emotion: Neural mechanisms and beyond, From Habits to Self-Regulation: How do we Change?, Yale University, New Haven, CT, USA

OECD. (2005). Teachers matter: Attracting, developing and retaining effective teachers. Paris: OECD.

Oplatka, I. (2007). Managing emotions in teaching: Toward an understanding of emotion displays and caring as nonprescribed role elements. The Teachers College Record, 109, 1374-1400.

Palfai, T. P., \& Salovey, P. (1993). The influence of depressed and elated mood on deductive and inductive reasoning. Imagination, Cognition and Personality, 13, 57-71.

Palomera, R., Fernandez-Berrocal, P., \& Brackett, M. A. (2008). Emotional intelligence as a basic competency in pre-service teacher training: Some evidence. Electronic Journal of Research in Educational Psychology, 6, 437-454.

Pedrabissi, L., Rolland, J. P., \& Santinello, M. (1993). Stress and burnout among teachers in Italy and France. Journal of Psychology, 127, 529-535.

Pisanti, R., Gagliardi, M. P., Razzino, S., \& Bertini, M. (2003). Occupational stress and wellness among Italian secondary school teachers. Psychology \& health, 18, 523-536.

Pithers, R. T., \& Soden, R. (1998). Scottish and Australian teacher stress and strain: A comparative study. British Journal of Educational Psychology, 68, 269-279.

Plutchik, R. (1994). The psychology and biology of emotion (first ed.). New York: Harper-Collins.

Plutchik, R. (2001). The nature of emotions. American Scientist, 89, 344-350.

Richards, J. M., \& Gross, J. J. (2000). Emotion regulation and memory: The cognitive costs of keeping one's cool. Journal of Personality and Social Psychology, 79, 410-424.

Rimm-Kaufman, S. E., Fan, X., Chiu, Y. J., \& You, W. (2007). The contribution of the responsive classroom approach on children's academic achievement: results from a three year longitudinal study. Journal of School Psychology, 45, 401-421.

Roberts, R. D., Zeidner, M., \& Matthews, G. (2001). Does emotional intelligence meet traditional standards for an intelligence? Some new data and conclusions. Emotion, 1, 196-231.

Rosiek, J. (2003). Emotional scaffolding: An exploration of the teacher knowledge at the intersection of student emotion and the subject matter. Journal of Teacher Education, 54, 399-412.

Salovey, P., Bedwell, T. B., Detweiler, J. B., \& Mayer, J. D. (2000). Current directions in emotional intelligence research. In M. J. Lewis \& J. M. Haviland-Jones (Eds.), Handbook of emotions (second ed., pp. 504-520). New York: Guilford Press.

Salovey, P., \& Mayer, J. D. (1990). Emotional intelligence. Imagination, Cognition and Personality, 9, 185-211. 
Schaps, E., Battistich, V., \& Solomon, D. (1996). School as a caring community: A key to character education. In A. Molnar (Ed.), Ninety-sixth yearbook of the National Society for the Study of Education (pp. 127-139). Chicago: University of Chicago Press.

Sheldon, B. (2011). Cognitive behavioural therapy, research and practice in health and social care (first ed.). Abingdon: Routledge.

Sheppes, G., \& Gross, J. (in press). Emotion regulation effectiveness: What works when. In T. H. A. \& S. J. M. (Eds.), Handbook of psychology, volume five: Personality and social psychology (pp. 281-291). New York, NY: Wiley.

Sheppes, G., \& Gross, J. J. (2011). Is timing everything? Temporal considerations in emotion regulation. Personality and Social Psychology Review, 15, 319-331.

Sheppes, G., Scheibe, S., Suri, G., \& Gross, J. J. (2011). Emotion-Regulation Choice. Psychological Science, 22, 1391-1396.

Sinha, R. (2007). The role of stress in addiction relapse. Current psychiatry reports, 9, 388-395.

Sinha, R., Fox, H. C., Hong, K. A., Bergquist, K., Bhagwagar, Z., \& Siedlarz, K. M. (2008). Enhanced negative emotion and alcohol craving, and altered physiological responses following stress and cue exposure in alcohol dependent individuals. Neuropsychopharmacology, 34, 1198-1208.

Srivastava, S., Tamir, M., McGonigal, K. M., John, O. P., \& Gross, J. J. (2009). The social costs of emotional suppression: A prospective study of the transition to college. Journal of Personality and Social Psychology, 96, 883-897.

Sue, S. (1999). Science, ethnicity, and bias: Where have we gone wrong? American Psychologist, 54, 1070-1077.

Suri, G., Sheppes, G., \& Gross, J. J. (in press). Emotion regulation and cognition. In M. D. Robinson, E. R. Watkins \& E. Harmon-Jones (Eds.), Handbook of cognition and emotion (pp. 281-291). New York, NY: Guilford.

Sutton, R., \& Wheatley, K. (2003). Teachers' emotions and teaching: A review of the literature and directions for future research. Educational Psychology Review, 15, 327-358.

Travers, C., \& Cooper, C. (1993). Mental health, job satisfaction and occupational stress among UK teachers. Work and Stress, 7, 203-219.

van Dick, R., \& Wagner, U. (2001). Stress and strain in teaching: A structural equation approach. British Journal of Educational Psychology, 71, 243-259.

Weare, K., \& Gray, G. (2003) What works in developing children's emotional and social competence and wellbeing?, London: Department for Education and Skills (research report no. 456). Available: http://publications.education.gov.uk/eOrderingDownload/RR456.pdf [accessed 20 March 2008].

Wentzel, K. R. (2002). Are effective teachers like good parents? Teaching styles and student adjustment in early adolescence. Child Development, 73, 287-301.

Whitcomb, J., Borko, H., \& Liston, D. (2008). Why Teach? Part II. Journal of Teacher Education, 59, 267-272.

Williams, L. E., Bargh, J. A., Nocera, C. C., \& Gray, J. R. (2009). The unconscious regulation of emotion: Nonconscious reappraisal goals modulate emotional reactivity. Emotion, 9, 847-854. 